\title{
Failure Prediction in Bulk Metal Forming Process
}

\author{
Ameen Topa and Qasim H. Shah \\ Department of Mechanical Engineering, International Islamic University Malaysia, Jalan Gombak, 53100 Kuala Lumpur, Malaysia
}

Correspondence should be addressed to Ameen Topa; ameen.topa@live.iium.edu.my

Received 25 August 2014; Accepted 13 October 2014; Published 10 November 2014

Academic Editor: Hailiang Yu

Copyright (C) 2014 A. Topa and Q. H. Shah. This is an open access article distributed under the Creative Commons Attribution License, which permits unrestricted use, distribution, and reproduction in any medium, provided the original work is properly cited.

\begin{abstract}
An important concern in metal forming is whether the desired deformation can be accomplished without defects in the final product. Various ductile fracture criteria have been developed and experimentally verified for a limited number of cases of metal forming processes. These criteria are highly dependent on the geometry of the workpiece and cannot be utilized for complicated shapes without experimental verification. However, experimental work is a resource hungry process. This paper proposes the ability of finite element analysis (FEA) software such as LS-DYNA to pinpoint the crack-like flaws in bulk metal forming products. Two different approaches named as arbitrary Lagrangian-Eulerian (ALE) and smooth particle hydrodynamics (SPH) formulations were adopted. The results of the simulations agree well with the experimental work and a comparison between the two formulations has been carried out. Both approximation methods successfully predicted the flow of workpiece material (plastic deformation). However ALE method was able to pinpoint the location of the flaws.
\end{abstract}

\section{Introduction}

In metal forming processes, the term workability refers to the degree of deformation that can be achieved in the workpiece without the occurrence of a defect, that is, the appearance of surface or internal cracks. Failure usually occurs as ductile fracture in metalworking and rarely as brittle fracture. The propagation of the cracks is of little interest as the main objective is to avoid their initiation. These cracks usually appear within regions that are highly strained due to extensive plastic flow of the material during the metal forming process [1].

The initiation of ductile fracture is a multistep process consisting of microvoid nucleation, growth, and then their coalescence [2]. Microvoids usually nucleate due to the debonding of the matrix material followed by a stage of void growth in which the microvoids grow under the applied stress state. The final phase of the ductile fracture happens when neighbouring microvoids coalesce together into a crack [3].

The occurrence of ductile fracture in metal forming process is a major limiting factor [4]. The prediction of the initiation of the cracks is important as it allows prior modification of the forming process which can result in sound and reliable products [5]. Therefore, the prediction of ductile fracture in metal forming processes has attracted the attention of many researchers for more than five decades [6] and has been extensively studied in literature with contributions from both academic and industrial research institutions [7].

The basic feature of bulk metal forming processes is the high volume to surface area ratio. Forging is an important bulk metal forming process in which metals are shaped into useful complicated structures [8]. In this process, the workpiece is compressed between two dies and undergoes large plastic deformation. The material flow is confined in the cavity between the dies and the extra material flows out through the gap between them $[9,10]$. In bulk metal forming, surface defects result from plastic instabilities associated with the localization phenomena while internal cracks result from the accumulation of damage during the deformation which depends on the stress and strain paths [4].

Due to the importance of ductile fracture in metal forming processes, tremendous efforts were made by different researchers to develop a valid criterion for surface and hidden ductile fractures [11]. Gouveia and coworkers studied four previously published ductile fracture criteria on ring, 
cylindrical, tapered, and flanged upset test samples [1]. Huang and Dong developed a new criterion for various deformation conditions based on the microvoid model and verified it in uniaxial tension, torsion, and upsetting conditions [12]. Reddy and coworkers investigated different ductile fracture criteria in axisymmetric drawing [4]. Kiran and Khandelwal proposed a new micromechanics ductile fracture criterion and calibrated it with ASTM A992 steels [11]. Goijaerts and coworkers focused on the ductile fracture initiation in metal blanking process [2]. Clift and coworkers experimentally evaluated various failure criteria in three types of metal forming processes: simple upsetting, axisymmetric extrusion, and strip compression and tension [5]. Ouali and coworkers studied the ductile fracture of aluminium alloys in bulk metal forming and attempted to predict the failure using multiscale and continuum damage mechanics models [13]. Rao and coworkers carried on a comparative evaluation of the theoretical failure criteria reported in the published literature. They concluded that no theoretical failure criterion can be described as truly geometry-independent for metal forming processes [6].

In the above mentioned work, it is clear that the available ductile failure criteria are not sufficient to predict the defects due to their dependence on various conditions and parameters such as the workpiece geometry, the temperature of the process, and the friction between workpiece and tool system. On the other hand, a combination of reduced experimental work and extensive numerical simulation may enable the user to obtain a reliable design. Therefore, in the suggested work, extensive finite element analysis would be carried out using arbitrary Lagrange Eulerian (ALE) and smooth particle hydrodynamics (SPH) formulations in LS-DYNA.

The main objective of conducting finite element analysis of metal forming processes is to provide necessary information for proper control and design of these processes [14]. The number of the required experimental trials is minimized. Thus, the development time and cost are reduced. Today, the development of inexpensive powerful computers technology and the application of finite element method (FEM) into user friendly programs have brought this technology forward. This evolution has more or less revolutionized the metal forming analysis $[15,16]$.

There are two methods to describe the deformation of a continuous medium. The first method is called the Lagrangian description in which the independent variables are the coordinate of a particle in the undeformed state. Lagrangian description is suitable for processes like forging, deep drawing, and sheet bending. The second method is the Eulerian description in which the independent variables are the coordinates of a material point in the deformed state. Eulerian description is convenient for processes like rolling, drawing, and extrusion. In the case of infinitesimal deformation, there is no need to make distinction between the two methods [17].

The Lagrangian approach is often not suitable in modelling fluid-like behaviour due the excessive deformation in the material. Severe mesh distortion can occur which may cause instability. However, in the arbitrary LagrangianEulerian (ALE) formulation, the materials flow through a fixed or moving mesh. Thus, ALE is a much better choice for modelling fluid-like behaviour [18].

Meshfree or meshless methods are available in LS-DYNA software. In meshfree methods, the physical structure is discretized with particles instead of elements. The shape functions and the approximation solutions are solved at the particles. Therefore, very large deformation is permitted since there is no mesh. Smooth particle hydrodynamics $(\mathrm{SPH})$ method was developed to avoid the limitations of mesh tangling during extreme deformation problem with the finite element method. SPH is proven to be a very useful tool in LS-DYNA that can simulate solid and fluid materials $[19,20]$.

\section{Theoretical Background}

2.1. Arbitrary Lagrangian Eulerian (ALE) Formulation. In large deformation problems, a reference system is required from which independent variables describing the kinematics and the statics of the material particles can be defined. In Lagrangian formulation, the reference system is connected to the body and evolves with it. It is denoted as Material Reference System (MRS). On the other hand, in Eulerian formulation, the reference system is fixed in space and every point of the material is connected to a set of coordinates in this invariant Spatial Reference System (SRS) [21].

The pros and cons of both formulations can be illustrated from Figure 1. The Lagrangian formulation has the advantage of less complex governing equations. However, the elements move with the deforming body. Thus, they may distort excessively which may result in numerical instabilities. Moreover, this makes it difficult to consider the non-materialassociated boundary conditions. On the other hand, in Eulerian formulation, the mesh remains stationary and the material freely moves within. The elements are fixed in space thus the boundary of the deforming body does not coincide with the elements everywhere. As a result, taking the material-associated boundary conditions into account is complicated [21-23].

The above-motioned shortcomings are encountered in large deformation problems and can be overcome with the arbitrary Lagrangian Eulerian formulation. In ALE formulation, the movement of the mesh is represented by a set of selfgoverning variables and the merits of both the Lagrangian and Eulerian formulations are achieved [24]. The reference configuration consists of a set of grid points in arbitrary motion in space. The grid points can move with material or remain stationary in space or even move with any arbitrary velocity as desired [23]. As shown in Figure 2, the elements nodal point displacements $(d \vec{v})$ are not coupled with material displacements $(d \vec{u})$ and the body can flow through the elements however their shapes are being controlled to prevent unbounded distortions. ALE formulation has been used in fluid mechanics [25], solid-fluid interaction analysis [26, 27], and has been generalized to solve the flow problems with Navier-Stokes equations [28]. Recently, ALE has been successfully used in nonlinear analysis in solid mechanics $[24,29]$. 

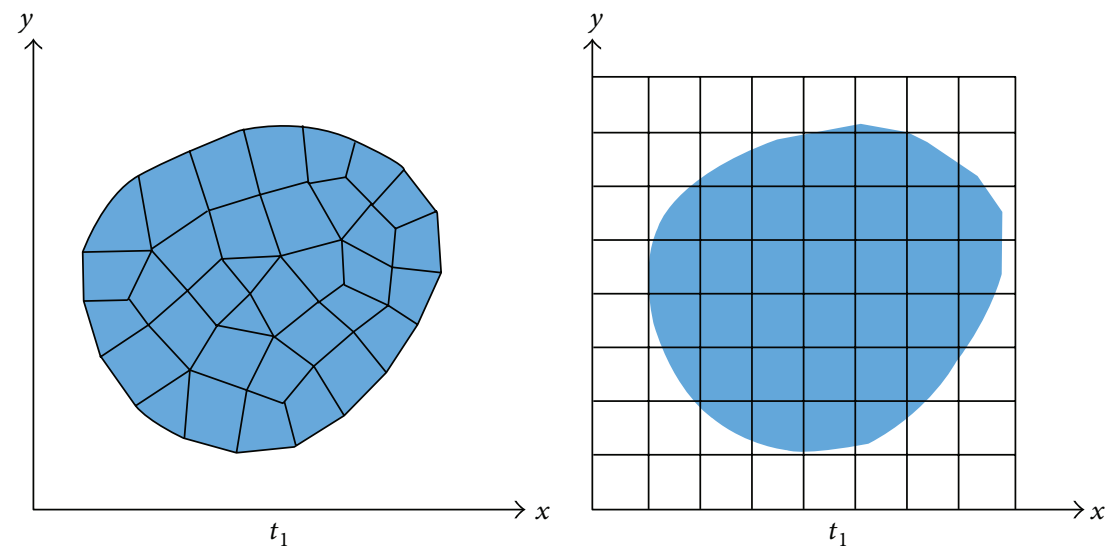

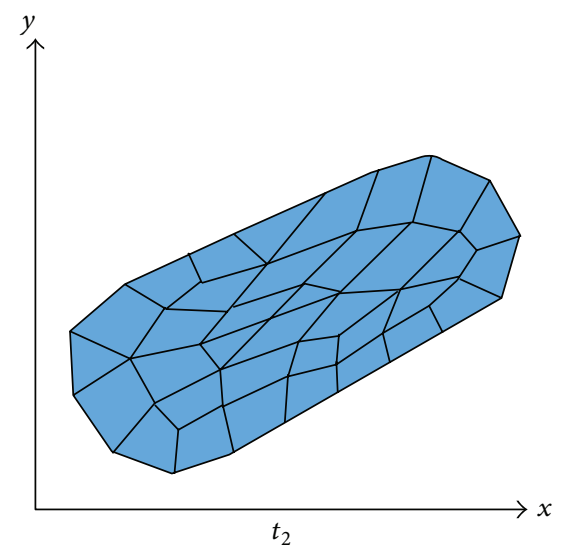

(a)

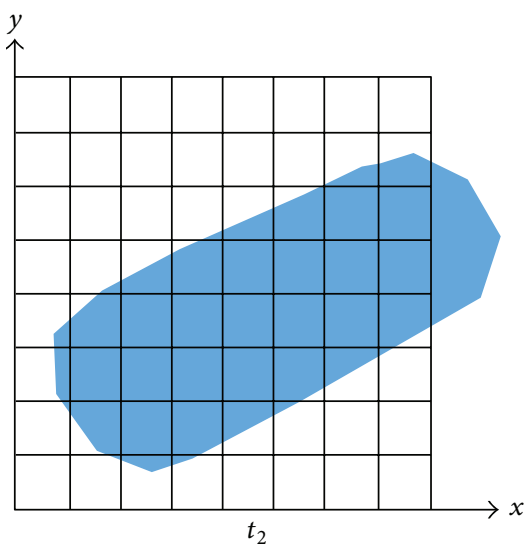

(b)

Figure 1: Lagrangian (a) and Eulerian (b) formulations.
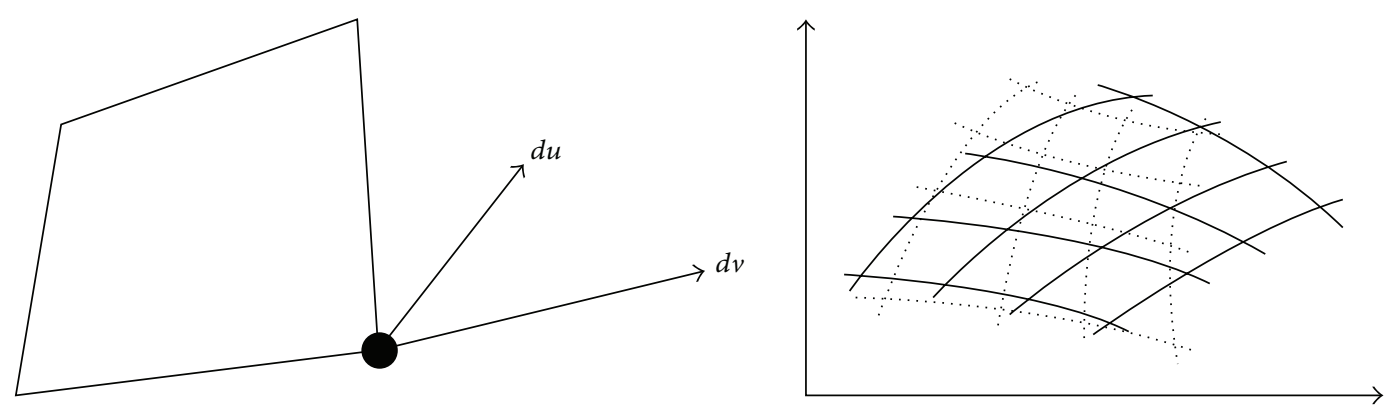

FIGURE 2: $d \vec{v}=$ mesh DOF, $d \vec{u}=$ material DOF, dotted line: material, and solid line: mesh [22].

2.2. Smooth Particle Hydrodynamics (SPH) Formulation. The Smooth particle hydrodynamics (SPH) formulation was first developed for astrophysical applications. It is a novel meshfree particle approach established on purely Lagrangian formulation [30]. However, it does not have a mesh as Lagrangian, Eulerian and arbitrary Lagrangian Eulerian methods. The body is defined by a number of mesh points or particles instead of a mesh and moves around in response to solid or fluid stresses produced by the interaction with neighbouring particles [31, 32] as illustrated in Figure 3. Since it is a particle based method and does not depend on fixed grids to track the material, it does not suffer from the inherent limitations of these methods. SPH is particularly well suited for flows with complex free surface behaviour and flows with complex physics such as the flow through industrial porous media [32].

In finite element methods, heavy remeshing might be required due to large plastic deformations in metal forming processes such as forging and extrusion. This increases the computational cost and may lead to inaccurate results. However, due to the meshfree nature of smooth particle hydrodynamics formulation, large deformations can be 

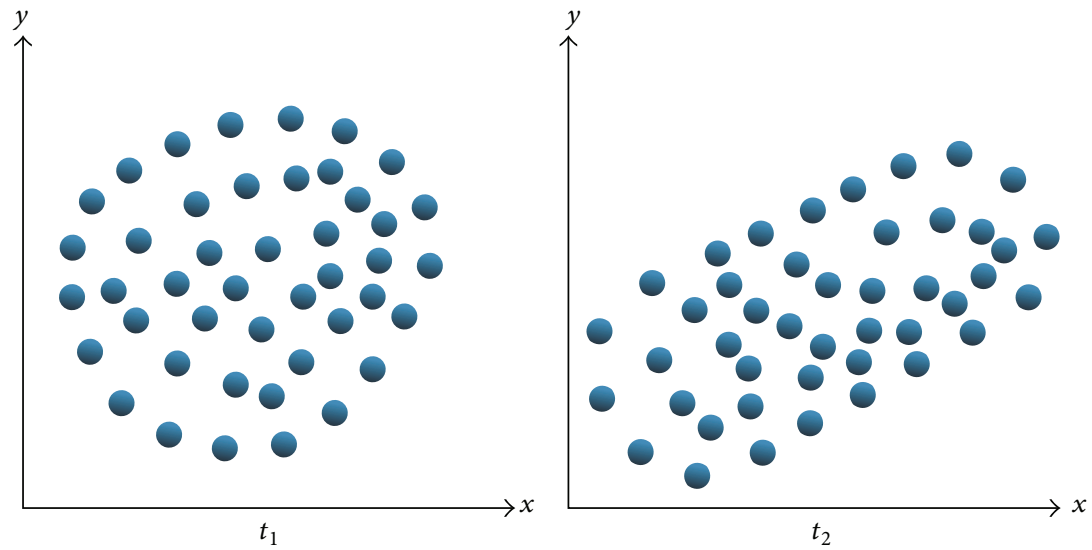

FIGURE 3: Smooth particle hydrodynamics formulation.

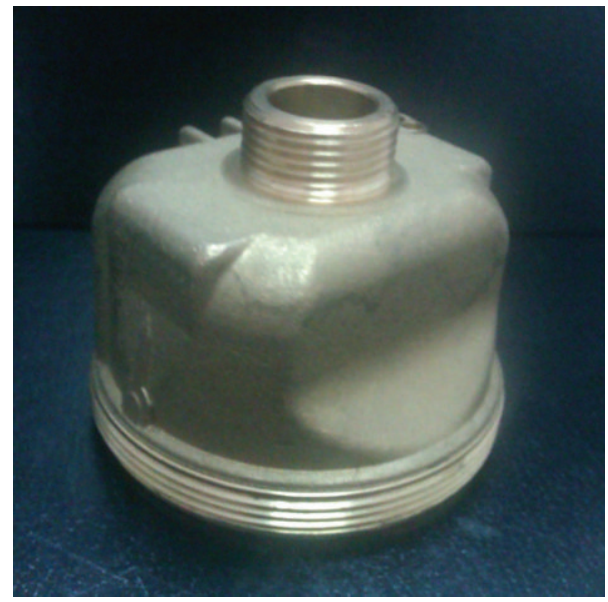

FIGURE 4: The hot forged part.

relatively easily handled. Moreover, it has the ability to follow the history dependent properties such as equivalent stress or plastic strain on a node-by-node basis, even during excessive deformation [33].

SPH formulation has been used widely in different applications. Droplet and thin film flow on smooth and rough fracture surfaces has been modelled with SPH method [34]. SPH formulation was adapted to simulate metal forming processes such as ring upsetting [35]. Crashworthiness optimization of foam filled tubes was performed using coupled SPH and finite element methods [36]. SPH method is used today in hypervelocity impact analysis [37], and its full potential is yet to be examined in detail.

\section{Experimental Work}

Hot forging process was carried out and the final forged part is shown in Figure 4 . The workpiece is brass cylinder with a diameter of $37 \mathrm{~mm}$ and a height of $64 \mathrm{~mm}$ as illustrated in Figure 5. The density of the brass used in this study is $8490 \mathrm{~kg} / \mathrm{mm}^{3}$. The workpiece is preheated to $800^{\circ} \mathrm{C}$ and then placed between a stationary die and a moving punch as shown

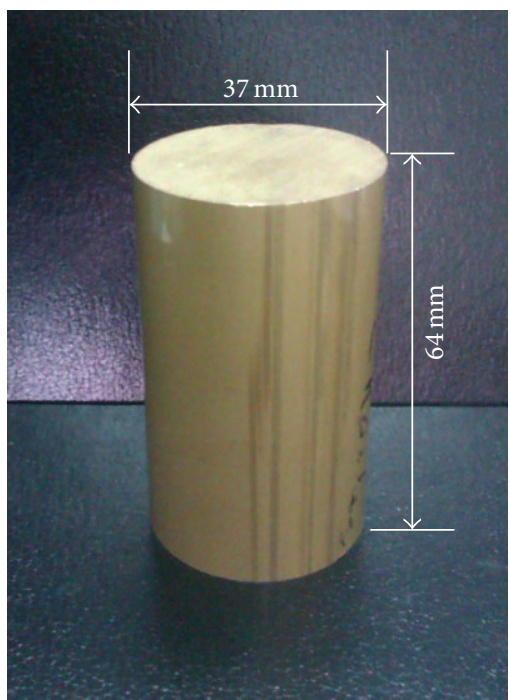

FIGURE 5: The workpiece geometry.

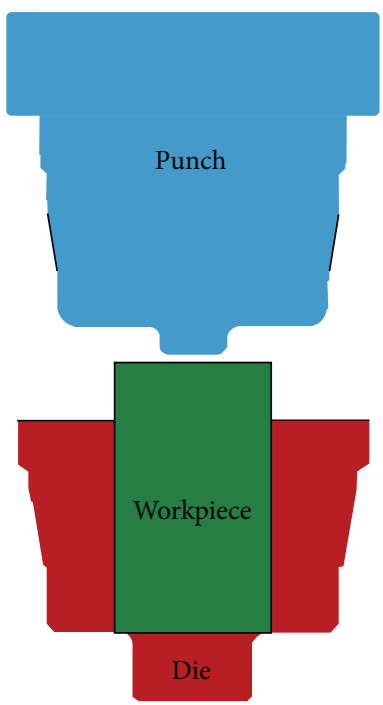

FIGURE 6: Experimental setup of the forging process (cross section view). 


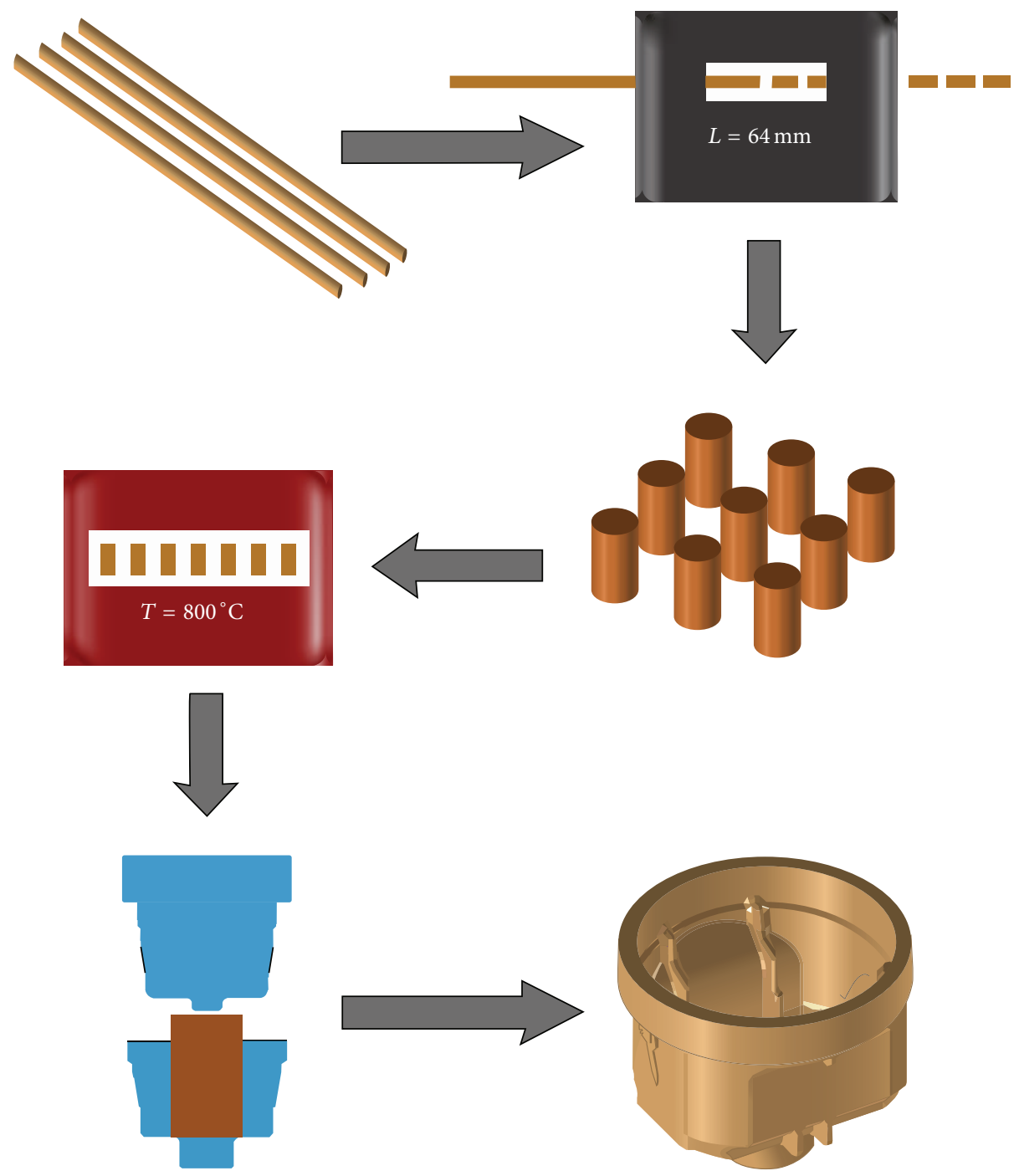

FIGURE 7: Schematic diagram of the experimental work.

in Figure 6. The punch compresses the workpiece at a velocity of approximately $10 \mathrm{~m} / \mathrm{s}$ until it reaches a distance of $3.7 \mathrm{~mm}$ from the bottom. The experimental steps are depicted in the schematic diagram in Figure 7.

The approximate location of the defects is shown in Figure 8. Inspecting several defective products shows that the cracks usually appear within a certain range located between the two ridges. One of the defective products is cut down and the crack location is pinpointed in Figure 9. The crack-like flaws result in the formation of new surfaces. For example, the new surfaces are illustrated in the micrograph $(\times 50)$ shown in Figure 10.

Upon thorough inspection, the wall thickness in the two ridges' side was found to be less than that in the rest of the product. This reduction in the thickness impedes the plastic flow of the material and is proposed to be the main source of the defects. The cross section of the product is shown in Figure 11, which clearly reveals the difference in the wall thickness of the product.
TABLE 1: Input values for the workpiece material model.

\begin{tabular}{lccc}
\hline Parameter & Description & Value & Units \\
\hline RO & Mass density & $8.490 E-06$ & $\mathrm{Kg} / \mathrm{mm}^{3}$ \\
$E$ & Young's modulus & 101 & $\mathrm{GPa}$ \\
PR & Poisson ratio & 0.31 & \\
SIGY & Yield strength & $0.65 E-03$ & $\mathrm{GPa}$ \\
ETAN & Tangent modulus & $0.225 E-03$ & $\mathrm{GPa}$ \\
\hline
\end{tabular}

\section{Finite Element Modelling}

The die and the punch were automatically meshed into shell rigid parts from the compatible CAD files (IGES) imported in the LS-DYNA preprocessor while the workpiece solid mesh was generated in the preprocessor as it is geometrically less complex. The material model used for the workpiece was MAT_PIECEWISE_LINEAR_PLASTICIY and the values used for the input parameters are shown in Table 1 . The values 


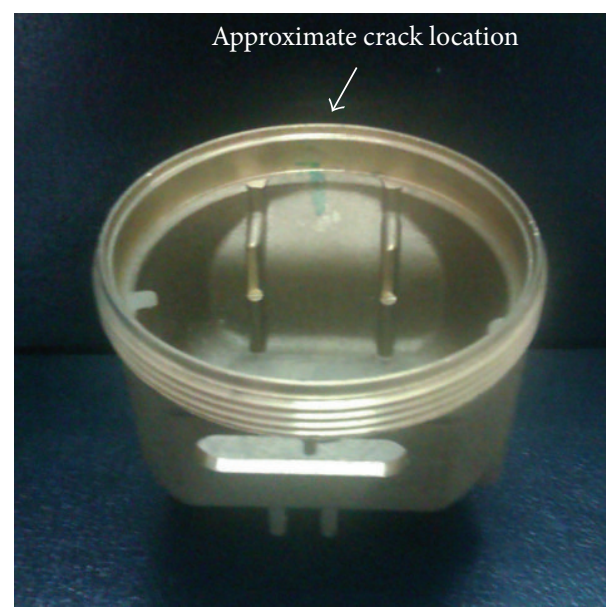

FiguRE 8: Approximate crack location.

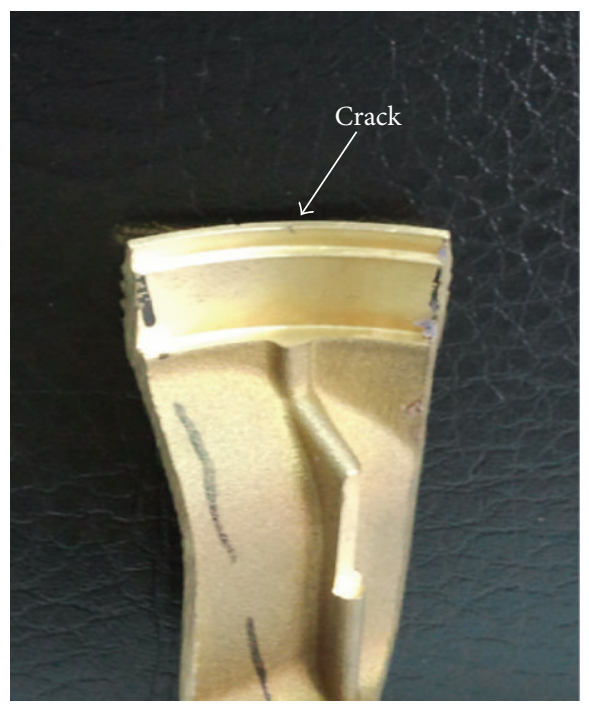

FIGURE 9: Identifying the location of the crack.

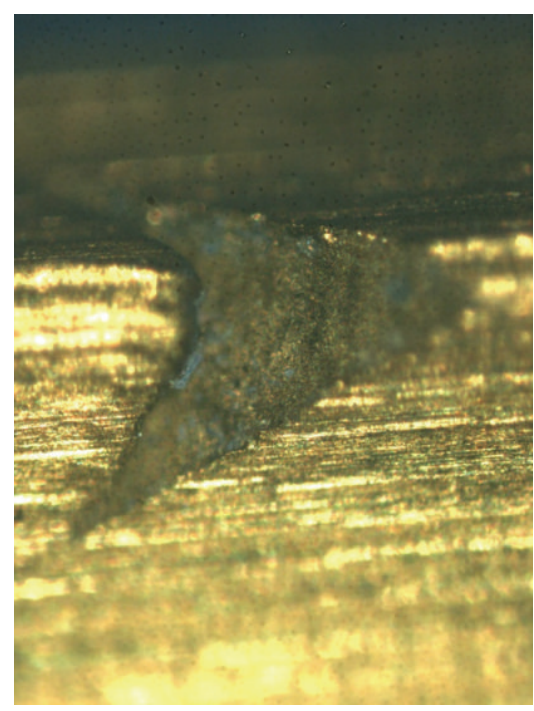

FIGURE 10: Free surface micrograph $(\times 50)$ of the work piece edge in Figure 8 .

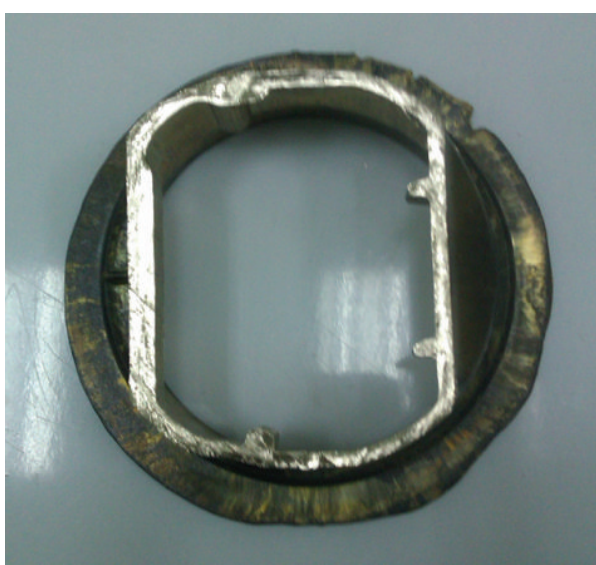

FIGURE 11: The difference in the wall thickness of the product.

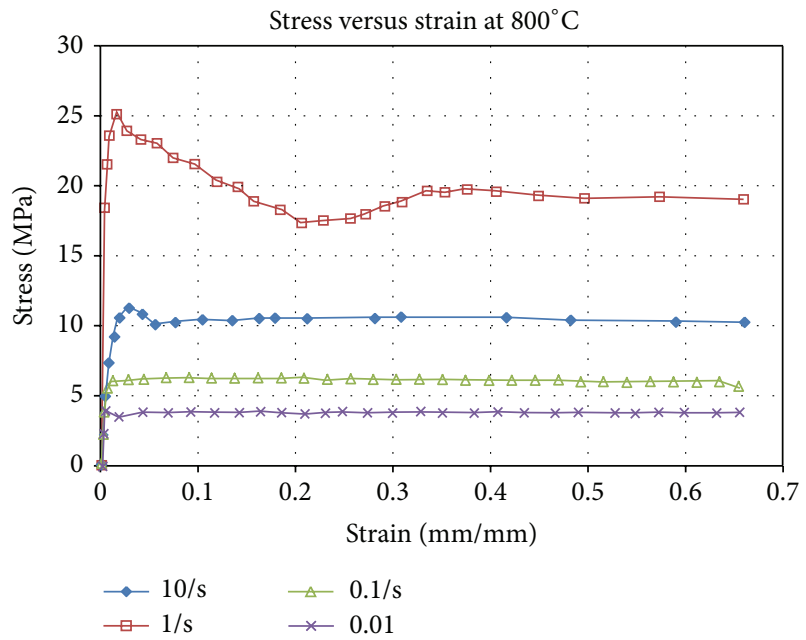

FIGURE 12: Stress-strain relationships for different strain rates at $T=$ $800^{\circ} \mathrm{C}$.

of Young's modulus and yield point at different strain rates were found in the literature [38]. The stress-strain curves for the material at different strain rates were obtained from previous work by Xiao and coworkers [39] and were plotted in Figure 12. Since the curves at different strain rates were used in the material model, the parameters $C$ and $P$ were ignored as they are used in calculating the strain rate effects [40].

4.1. Smooth Particle Hydrodynamics (SPH) Formulation. The cylindrical workpiece was discretized into particles while the die and tool were meshed using shell elements. In SPH, the bulk viscosity must be defined to get more realistic results. The bulk viscosity has two coefficients, the quadratic viscosity coefficient and the linear viscosity coefficient. The first coefficient is important to smear the shocks and prevent elements from collapsing while the second coefficient is used to damp oscillation $[41,42]$. Both coefficients are increased by a factor of 10 for soft materials [43]. The default formulation of the particle approximation theory was used. Other approximations would cause calculation instabilities. 
TABLE 2: Input values for CONTROL_ALE card.

\begin{tabular}{llc}
\hline Parameter & Description & Value \\
\hline DCT & Default continuum treatment & 2 \\
NVAD & Number of cycles between advections & 1 \\
METH & Advection method & 3 \\
AFAC & ALE smoothing weight factor & -1 \\
\hline
\end{tabular}

The contact was defined with CONTACT_AUTOMATIC_NODES_TO_SURAFCE. A node set which contains all the SPH particles was defined and used as the SLAVE (workpiece) in the contact card. Furthermore, for SPH particles representing a volume, the contact thickness STT is suggested to be $0.8-1.0 \mathrm{~mm}$ to avoid nodal release [44]. To prevent contact penetration, the penalty stiffness scale factors SFS and SFM must be increased to 10 .

4.2. Arbitrary Lagrangian Eulerian (ALE) Formulation. ALE formulation is suitable for modelling large deformation problems and fluid-like behaviour as the material flows through a fixed or a moving mesh [18]. For simplicity, the effect of the air was ignored and it is assumed to be void in the simulation. Both the die and punch are modelled as rigid while the workpiece is modelled as solid ALE material which is permitted to deform and flow into the surrounding space (void). The mesh of the workpiece and the void should share the same nodes on their common boundaries [45].

Element formulation 12 was chosen for the workpiece. This formulation stands for one-point integration with single material and void. The nondefault input values of the CONTROL_ALE card are shown in Table 2. The selected values were used to obtain more reliable results $[46,47]$.

The interaction between the Lagrangian (die and tool) and ALE (workpiece and void) parts was defined under CONSTRAINED_LAGRANGE_IN_SOLID card. This card is very important and the values of its parameters should be chosen carefully. Otherwise, leakage problem and instabilities may occur. Table 3 shows the input values of this card. These values were adopted from previous works $[48,49]$.

\section{Results and Discussion}

5.1. Smooth Particle Hydrodynamics (SPH) Formulation. The contours of the equivalent von Mises stress are shown in Figure 13. Any point of the material can be traced using the SPH method. Thus, the initial and final positions of any point in the material can be found. The rate of deformation varies with time. It can be observed that as the rate of deformation is higher near the end of the compression phase, the strain rate increases at this stage. However, since stressstrain relationship at different strain rates was defined in the material model, the strain rate effects are considered in the calculations.

The increase in the rate of deformation can be explained with the help of Figure 14 . The flow velocity of the material depends on the volumetric flow rate and the cross sectional area perpendicular to the flow velocity [50]. The increase
TABLE 3: Input values for CONSTRAINED_LAGRANGE_IN_ SOLID card.

\begin{tabular}{llc}
\hline Parameter & Description & Value \\
\hline NQUAD & Number of quadrature & 3 \\
points & 4 \\
DIREC & Coupling type & 2 \\
PFAC & Coupling direction & 1 \\
ILEAK & Penalty factor & 0 \\
FRCMIN & Leakage control & 0.3 \\
PLEAK & $\begin{array}{l}\text { Minimum volume fraction } \\
\text { to activate coupling }\end{array}$ & 0.1 \\
PFACMM & $\begin{array}{l}\text { Leakage control penalty } \\
\text { factor }\end{array}$ & 3 \\
\hline
\end{tabular}

in the flow velocity of the material is due to the decrease of the flow area, which can be observed from Figure 14. As the compression reaches its end, material flow becomes more restricted due to reduced thickness through which it passes.

Analyzing Figure 13 shows that at time $t=1 \mathrm{~ms}$, the maximum equivalent stress occurs almost at any point in workpiece model. Afterwards, the maximum equivalent stress occurs only in the internal points. This can be explained with the help of Figure 14. At the initial states, the process can be roughly considered as a standard one-dimensional compression test. However, as the compression continues, due to the convex shape of the punch and the concave shape of the die, the force distribution on the upper and lower surface of the workpiece will vary and shear stress will be generated.

5.2. Arbitrary Lagrangian Eulerian (ALE) Formulation. For the ALE formulation, the contours of the effective plastic strain are illustrated in Figure 15. ALE formulation gives clearer view of the shape of the material compared to $\mathrm{SPH}$ formulation. ALE method represents the volume (solid elements) of the material by surfaces while SPH method is represented by particles. Sharp edges are visible with ALE formulation in contrast to SPH formulation.

Towards the end of the compression, namely, at $t=6 \mathrm{~ms}$, it can be observed that there is a separation in the workpiece material; that is, there is a brief discontinuity in the material flow. To have a better view of this phenomenon, the section view is presented in Figure 16. The start of discontinuity of the material flow can be seen at $t=6 \mathrm{~ms}$. This can be interpreted as a result of the sudden increase in the flow velocity. As discussed earlier, the flow velocity increases as the compression comes to its end. This increase of flow velocity is more in the material on the free edges of the flow which causes the material on that portion to "splash" away. It is proposed that this phenomenon causes the cracks in the bulk metal forming. The cracks occur on the side of the ridges where the wall thickness is minimum as shown Figure 17. The wall thickness obtained from the simulations matches the experimental results. 

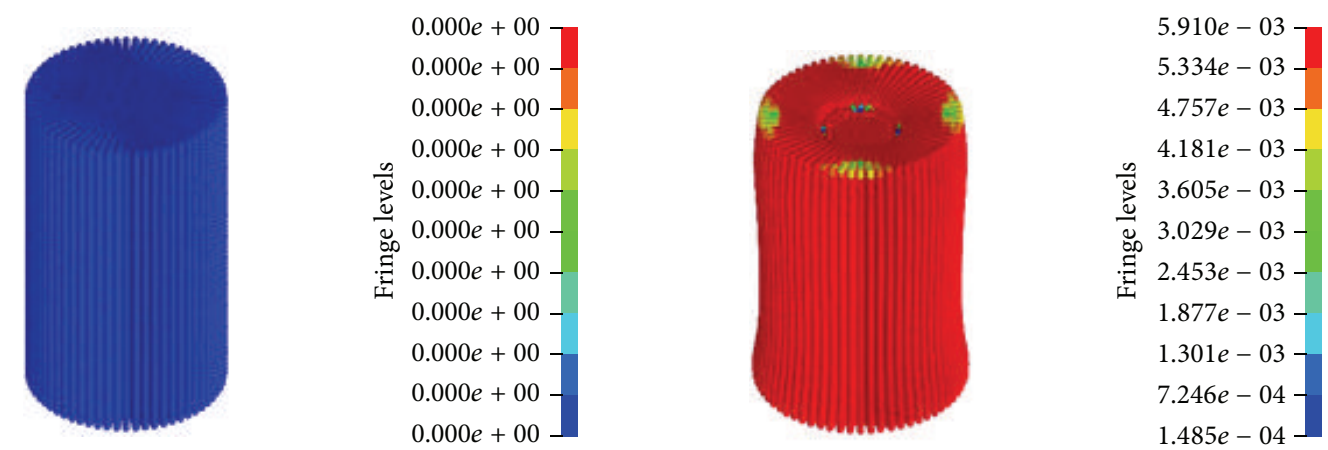

$$
t=0 \mathrm{~ms}
$$

$$
t=1 \mathrm{~ms}
$$
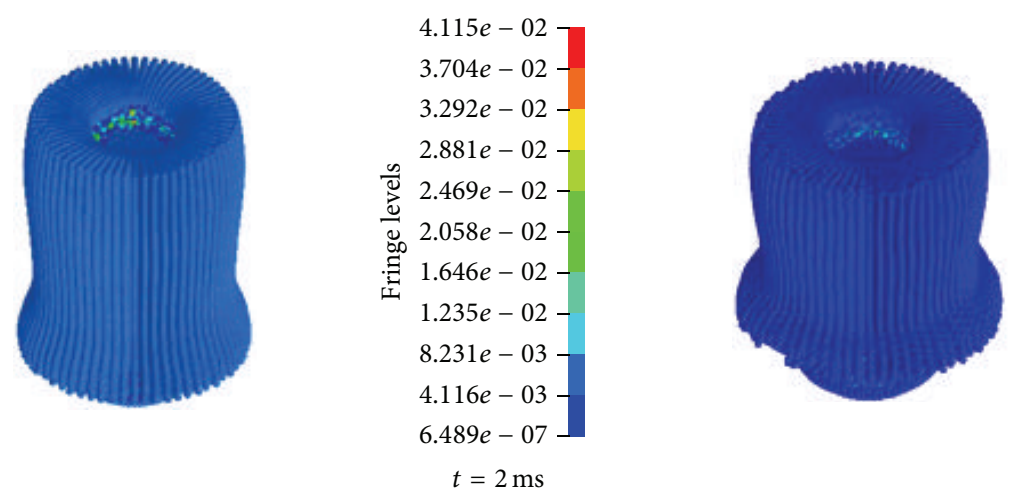

$$
\begin{aligned}
& 1.341 e-01 \\
& 1.207 e-01- \\
& 1.073 e-01-
\end{aligned}
$$

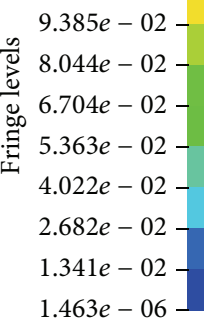

$$
\begin{aligned}
& t=3 \mathrm{~ms}
\end{aligned}
$$
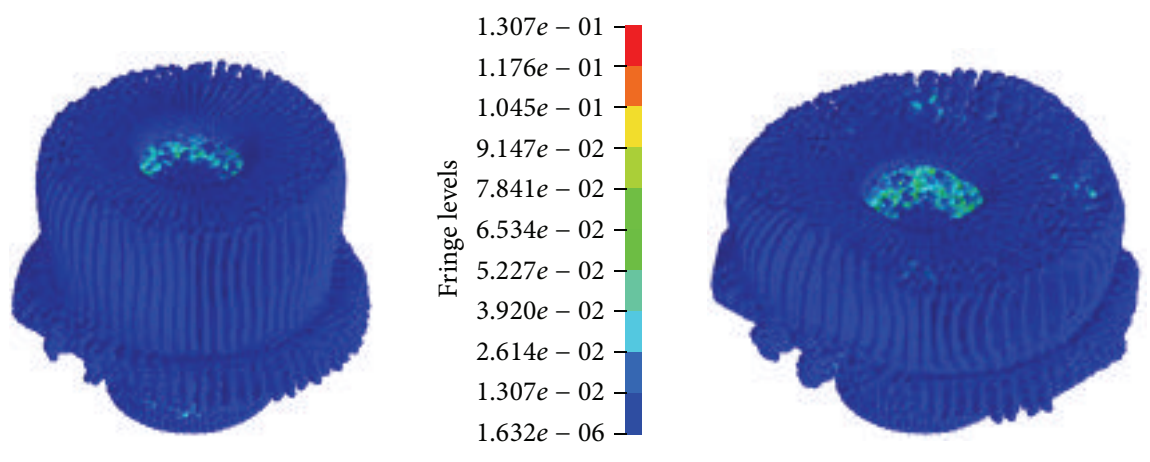

$1.686 e-01$

$$
\begin{aligned}
& 1.517 e-01- \\
& 1.349 e-01- \\
& 1.180 e-01- \\
& t=5 \mathrm{~ms}
\end{aligned}
$$
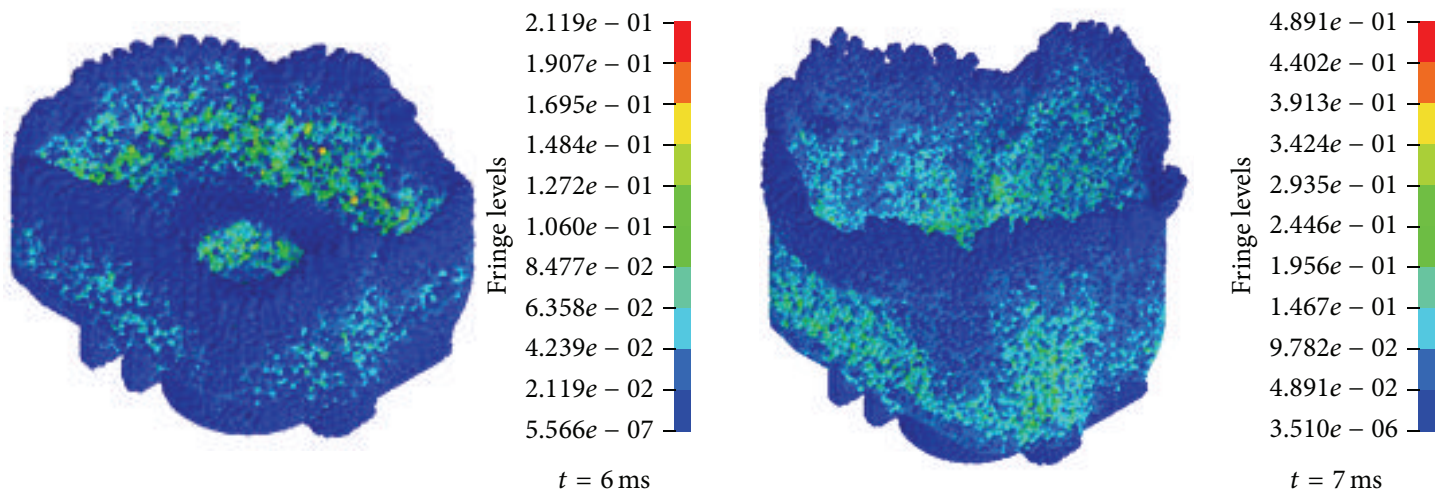

FIgURE 13: The deformation and the equivalent von Mises stress contours using SPH. 

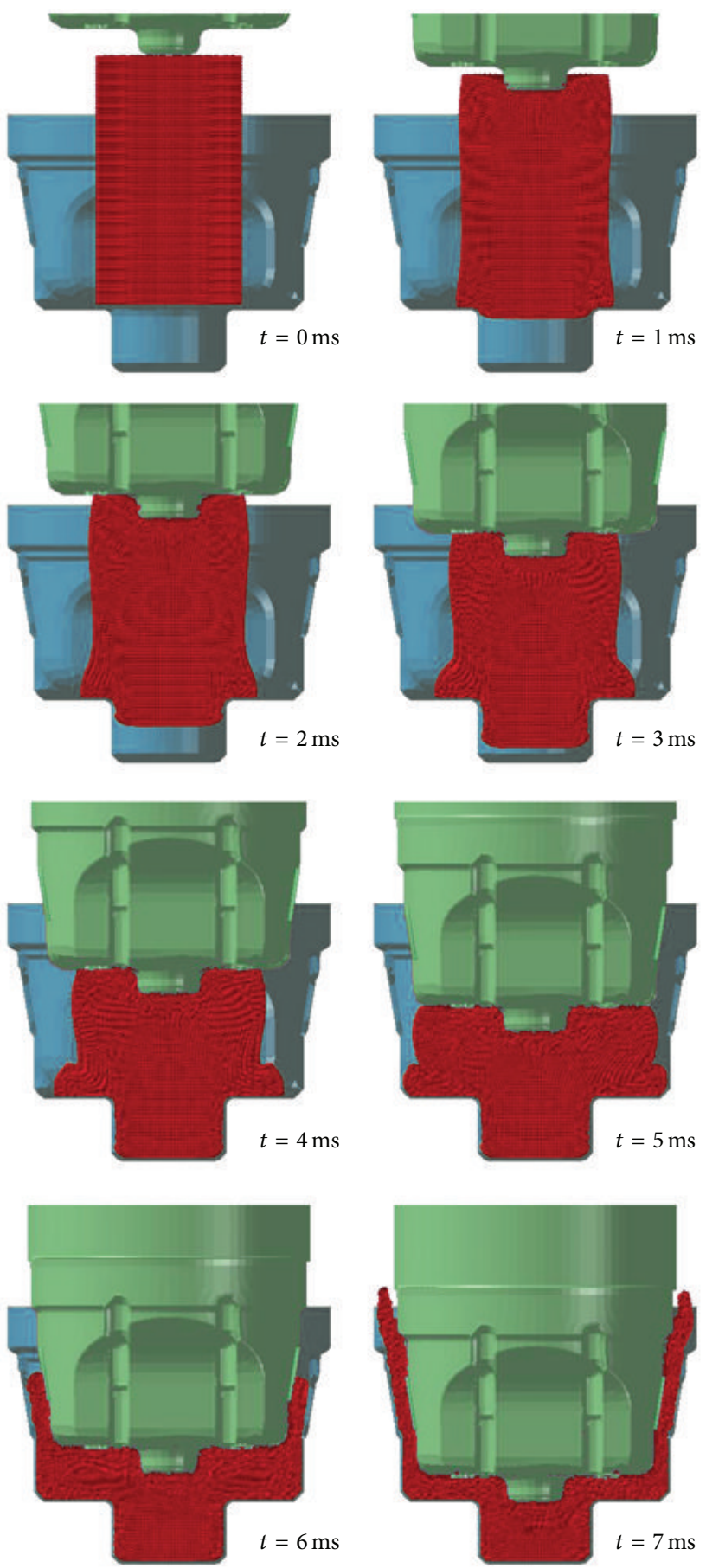

FIGURE 14: Section view normal the symmetry plane (SPH).

The velocity plot of four nodes initially located at the top surface of the workpiece is shown in Figure 18. It is observed that there is a sudden change in the velocity of three of these nodes towards the end of compression. These nodes travel from the top surface of the workpiece to the edges of the final product as shown in Figure 19. The sudden change in the velocity is not observed in node number 423615 which travels only from the top to the bottom of the workpiece. There is a tendency of the material at the edges to separate and form new surfaces. As the velocity of the workpiece material decreases at the end of the compression, the rejoining of the material occurs. However, some of the free surfaces which previously existed may not completely rejoin leaving flaws in the final product.

This "splash" effect occurs due to the fluid-like behaviour of the workpiece material. Thus, reducing the temperature of the process may prevent this effect. However, reducing the temperature means that more compression force is required. 

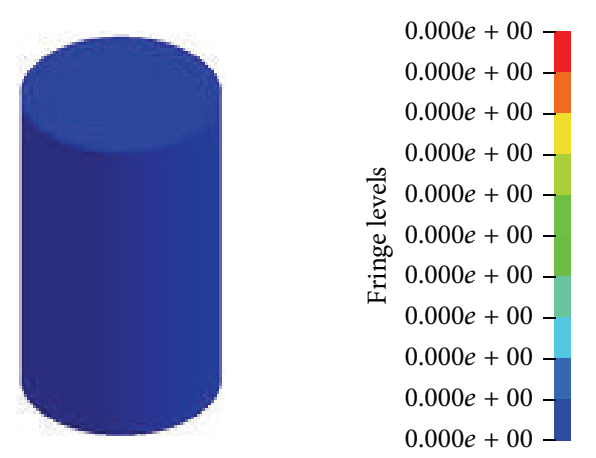

$$
t=0 \mathrm{~ms}
$$
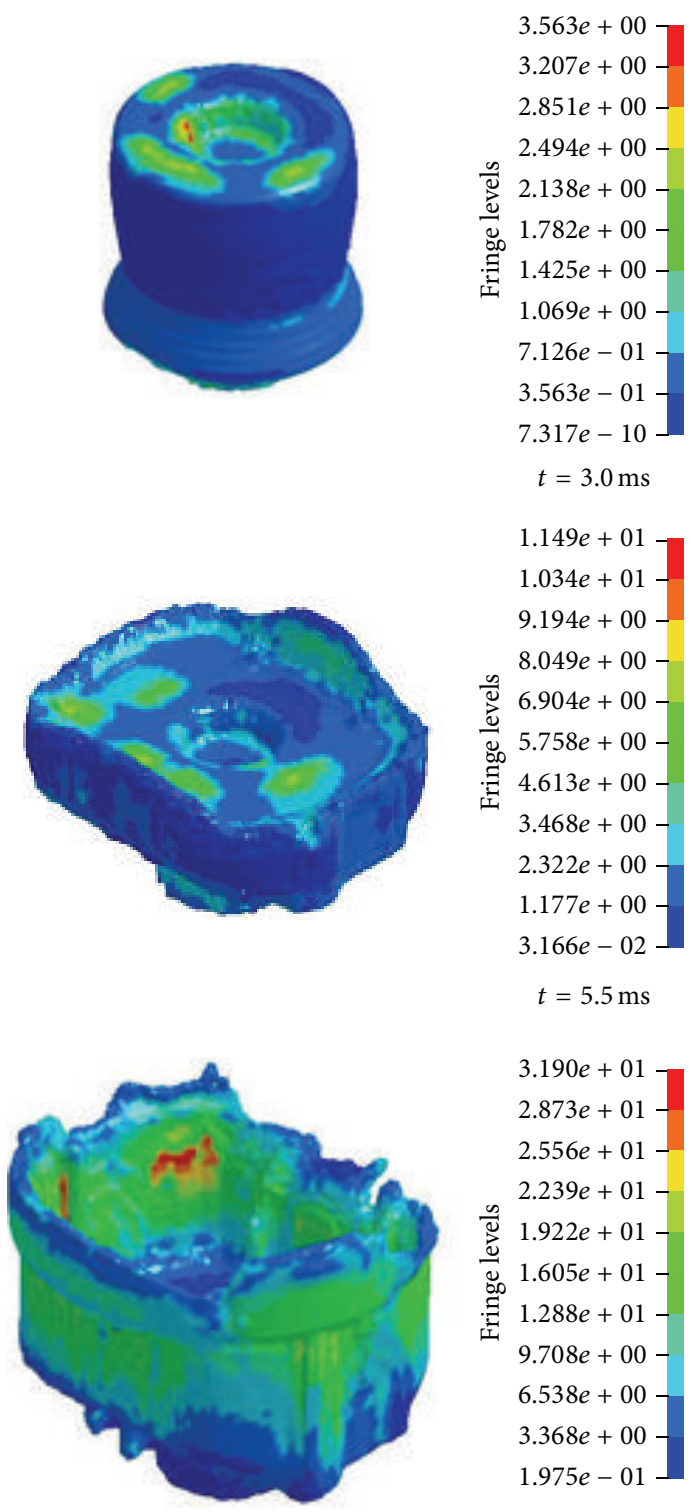

$1.149 e+01$ $1.034 e+01$ $9.194 e+00$ $8.049 e+00-$ $\stackrel{0}{\stackrel{2}{*}} 6.904 e+00-$ $\approx 5.758 e+00-$ 寻

$3.468 e+00$ $2.322 e+00$ $1.177 e+00$ $3.166 e-02$

$t=5.5 \mathrm{~ms}$
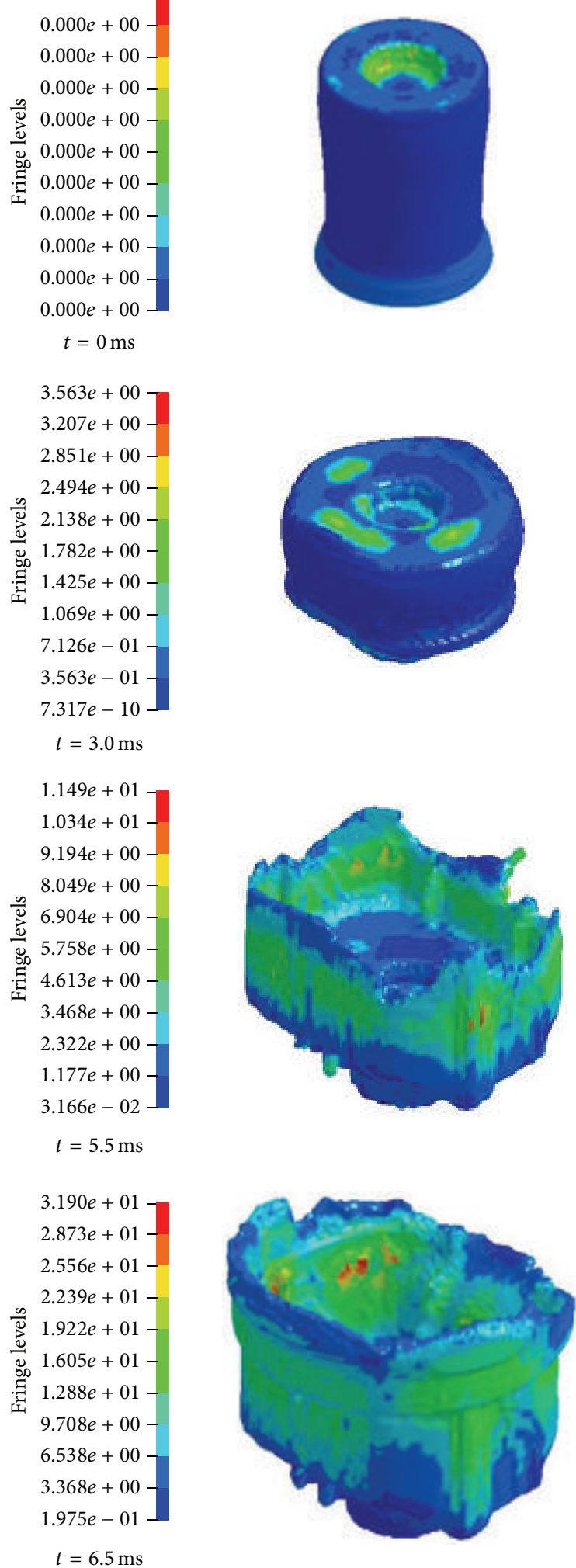

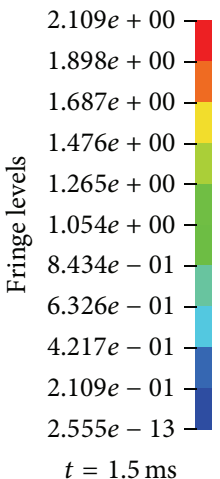

$8.985 e+00$ $8.086 e+00-$ $7.188 e+00-$ $6.289 e+00-$ \& $5.391 e+00-$ ㄴ. $4.492 e+00$ $\Xi 3.594 e+00-$ $2.695 e+00-$ $1.797 e+00$ $8.985 e-01-$ $4.680 e-08$ $t=4.5 \mathrm{~ms}$

$1.832 e+01$ $1.650 e+01$ $1.468 e+01$ $1.285 e+01-$ 总 $1.103 e+01-$ s. $9.207 e+00-$ $7.384 e+00-$ $5.560 e+00-$ $3.737 e+00$ $1.914 e+00-$ $9.051 e-02$ $t=6.0 \mathrm{~ms}$

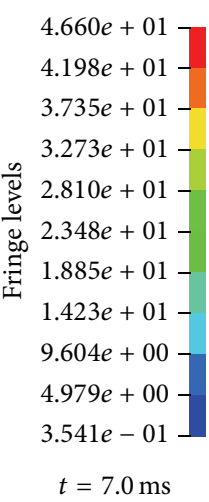

$t=7.0 \mathrm{~ms}$

FIGURE 15: The deformation and the effective plastic strain using contours ALE. 

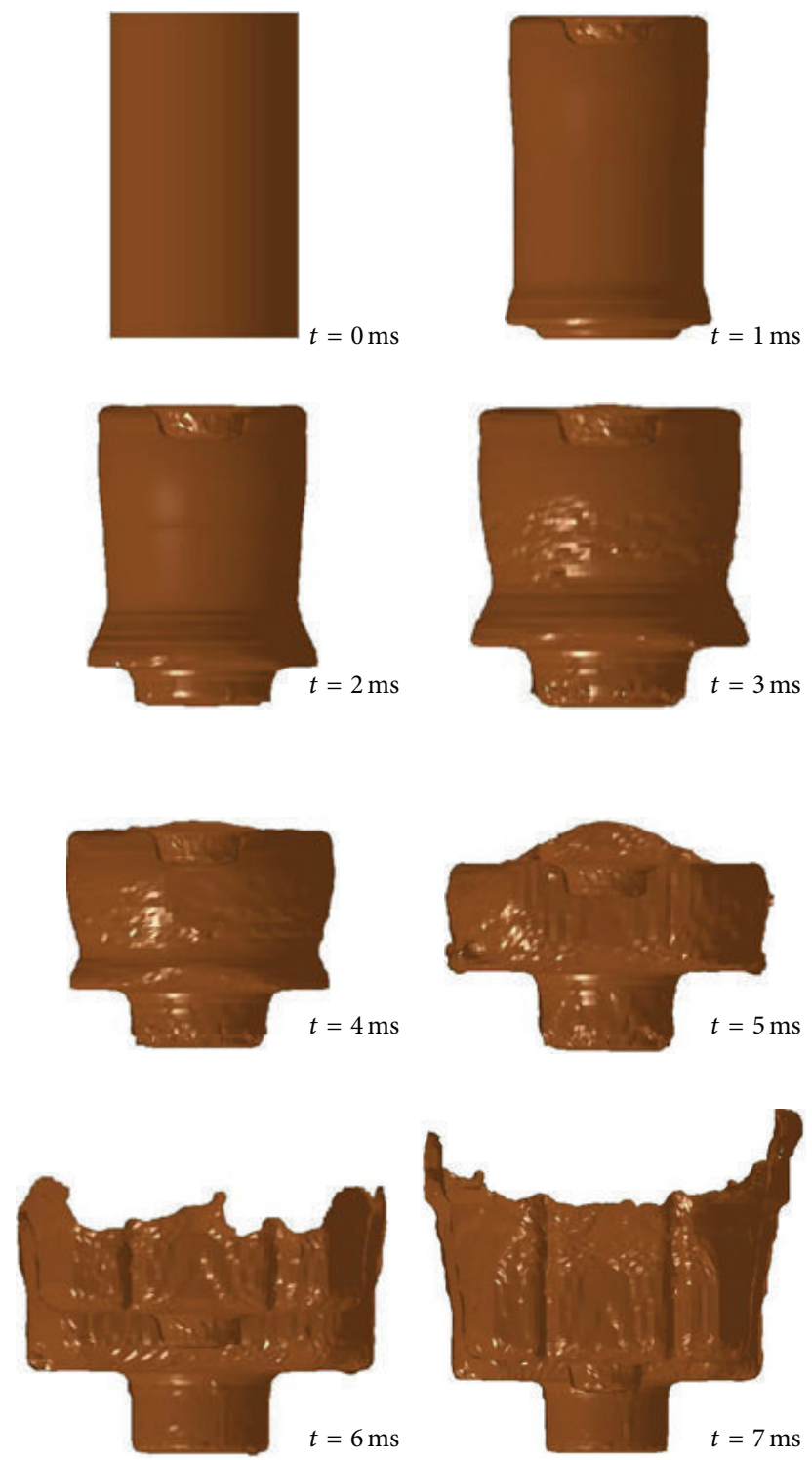

FIGURE 16: Section view normal the symmetry plane (ALE).

Therefore, it might not be a feasible solution. If the compression velocity were reduced, the magnitude of the sudden increase in the flow velocity would reduce. This might stop the formation of new surfaces. However, this would result in more production lead time. Another solution is to alter the design of the die and tool by increasing gap between them and thus increase the area through which the material flows. But this would require more material to produce the same product. A combination between the three previous solutions would give the optimum results.

5.3. $S P H$ versus $A L E$. With the input parameters mentioned in Section 4, the simulation was solved successfully for both SPH and ALE methods. However, SPH formulation took considerably less computational time than ALE formulation and the time step was almost constant.

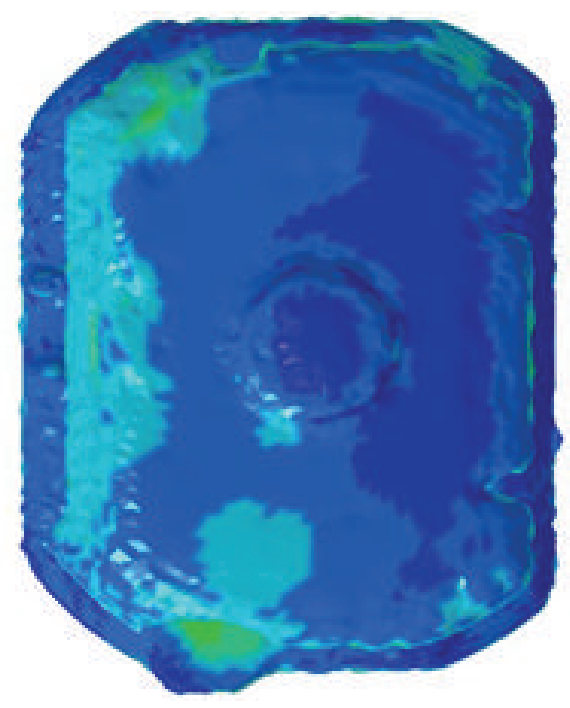

Figure 17: Cross section view showing the difference in the wall thickness near the ridges.

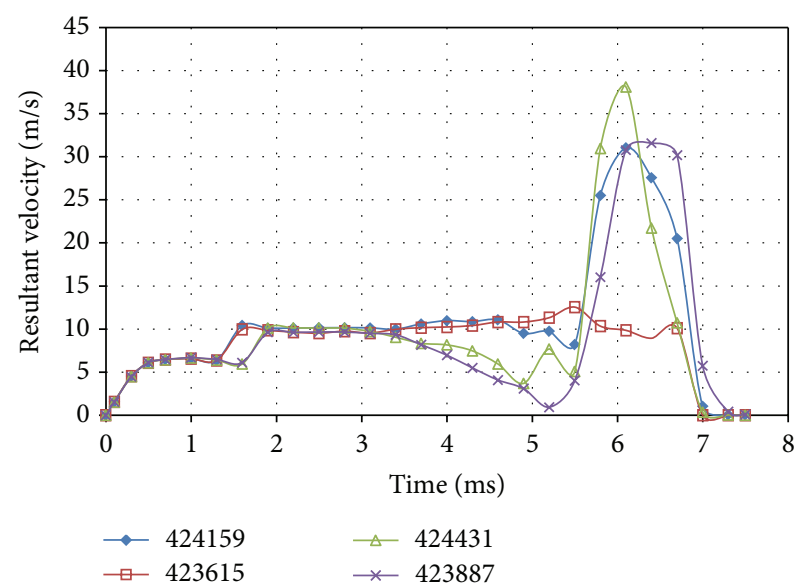

FIGURE 18: The resultant velocity of nodes initially located at top surface of the workpiece.

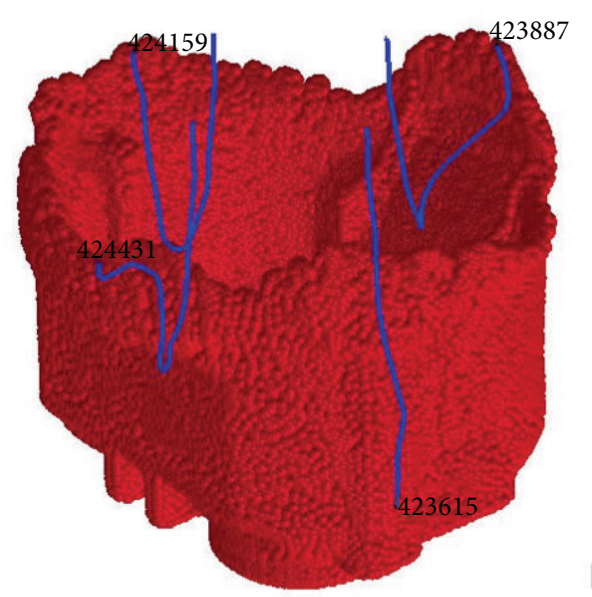

FIGURE 19: Tracing the displacement of four nodes originally located at the top surface of the workpiece. 

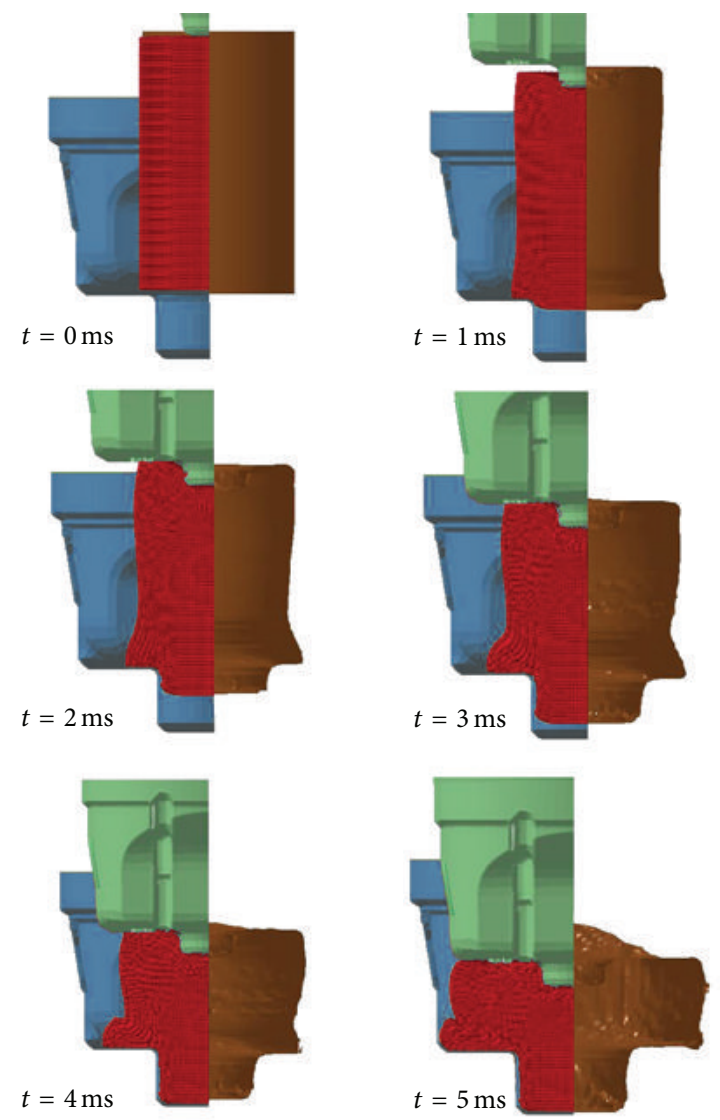

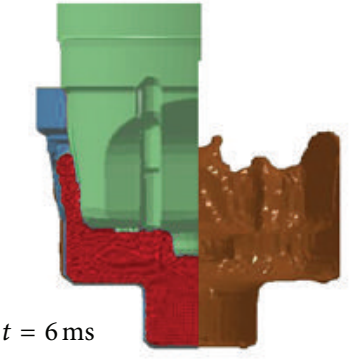

(a)

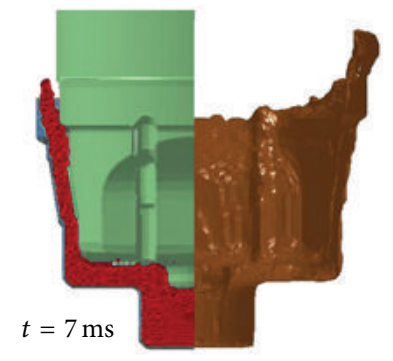

(b)

FIGURE 20: Comparison between the deformation with SPH (a) and ALE (b).

To compare the deformation in SPH and ALE, the section views were displayed side by side, as depicted in Figure 20. The material flow in SPH is more regular compared to the flow in ALE. The flow is roughly symmetric with SPH formulation as seen in Figure 14. However, in ALE formulation, the flow is unsymmetrical. With reference to Figure 20, it is observed that the initial and final states of the deformation are roughly the same. However, the deformation during the process is not similar.

One advantage of SPH method over ALE method is that the value of the contours at any point inside the material can be found by using a cutting plane. However, as mentioned before, ALE method represents the volume of the material with surfaces; thus, the state of the material under the surface cannot be found.
As stated in the introduction, bulk metal forming is a complex process yet a straightforward and symmetric deformation is achieved with SPH formulation. ALE formulation gives a more realistic deformation pattern and was able to predict the location of the possible flaws.

5.4. Ductile Fracture Model. A thorough study in the vast literature on ductile facture modelling reveals the limitation of the predictive capability of the ductile fracture models presently available. The drawback of these fracture models is their strong dependence on the application. However, Aretz and coworkers developed a simple ductile fracture model for problems of any stress triaxialities for sheet metal forming [51]. The failure in our study occurs when the thickness is 
greatly reduced; therefore the process can be considered as sheet metal forming in those regions. The developed criterion was established on Freudenthal ductile fracture model [5] in which the failure occurs when the plastic work density denoted by $w^{p}$ reaches a critical value at fracture $w_{f}^{p}$ as follows:

$$
\int_{0}^{w_{f}^{p}} d w^{p} \leq w_{f}^{p}
$$

However, in engineering practice, the work-based Freudenthal model is not as convenient as the strain-based version which can be obtained by realizing the work-conjugated definition of equivalent plastic strain given by

$$
d w^{p}=\boldsymbol{\sigma}: d \varepsilon^{p}=\bar{\sigma} \cdot \bar{\varepsilon} .
$$

Therefore, the strain-based version of Freudenthal model is as follows:

$$
\int_{0}^{\bar{\varepsilon}_{f}} d \bar{\varepsilon} \leq \bar{\varepsilon}_{f}
$$

where $\bar{\varepsilon}_{f}$ is the equivalent plastic strain at fracture. The back draw of this ductile facture model is the incapability of discriminating compressive and tensile stress states. However, ductile fracture in solids is considerably delayed in the existence of compressive stress states while it is accelerated in tensile ones. The modified Freudenthal ductile fracture model proposed by Aretz includes a transition function which depends on the loading mode parameter $\alpha$. The transition function is given by

$$
g(\alpha)=\left(\frac{1+\alpha}{2}\right)^{A}, \quad A \geq 0
$$

The parameter $A$ is a material dependent parameter. The purpose of the transition function $g(\alpha)$ is to determine the damage accumulation by the stress states. In the case of pure compressive stress states $(\alpha=-1)$, the transition function disappears. Thus, the contribution to damage accumulation becomes zero. The modified Freudenthal ductile fracture model becomes

$$
\int_{0}^{\bar{\varepsilon}_{f}} g(\alpha) d \bar{\varepsilon} \leq \bar{\varepsilon}_{f} .
$$

The present work mainly focuses on the prediction of failure through numerical simulations and highlights the important parameters in setting up the finite element model. Furthermore, it analyses the failure mechanism. The modified Freudenthal ductile fracture model will be used and coupled with the numerical simulations in future work. Moreover, the model will be utilized to eliminate the flaws in the product.

\section{Conclusions}

A complex shape product was produced from a simple cylindrical workpiece using hot forging process. Occasionally free surfaces and internal cracks were observed in the hot forged part. The forging process was simulated using SPH and ALE methods in LS-DYNA. The setup of the FEA modelling and the important parameters were discussed. The results of the numerical simulations show that both ALE and SPH methods are able to capture the large plastic deformation in the workpiece precisely. However, the ALE method played a prominent role in pinpointing the possible crack location.

The sudden increase of the material flow which causes the "splash" away effect is believed to be the reason for the occurrence of surface and internal cracks. Therefore, three solutions were proposed: to reduce the compression velocity, to reduce the temperature of the process, and to alter the design of the die and tool.

\section{Conflict of Interests}

The authors declare that there is no conflict of interests regarding the publication of this paper.

\section{Acknowledgments}

The authors gratefully acknowledge the support of Research and Management Centre (RMC) of International Islamic University Malaysia (IIUM). This work was supported by Research Grant (EDW B12-407-0885).

\section{References}

[1] B. P. P. A. Gouveia, J. M. C. Rodrigues, and P. A. F. Martins, "Ductile fracture in metalworking: experimental and theoretical research," Journal of Materials Processing Technology, vol. 101, no. 1, pp. 52-63, 2000.

[2] A. M. Goijaerts, L. E. Govaert, and F. P. T. Baaijens, "Prediction of ductile fracture in metal blanking," Journal of Manufacturing Science and Engineering, vol. 122, no. 3, pp. 476-483, 2000.

[3] K. Khandelwal and S. El-Tawil, "A finite strain continuum damage model for simulating ductile fracture in steels," Engineering Fracture Mechanics, vol. 116, pp. 172-189, 2014.

[4] N. V. Reddy, P. M. Dixit, and G. K. Lal, "Ductile fracture criteria and its prediction in axisymmetric drawing," International Journal of Machine Tools and Manufacture, vol. 40, no. 1, pp. 95111, 2000.

[5] S. E. Clift, P. Hartley, C. E. N. Sturgess, and G. W. Rowe, "Fracture prediction in plastic deformation processes," International Journal of Mechanical Sciences, vol. 32, no. 1, pp. 1-17, 1990.

[6] A. V. Rao, N. Ramakrishnan, and R. K. Kumar, "A comparative evaluation of the theoretical failure criteria for workability in cold forging," Journal of Materials Processing Technology, vol. 142, no. 1, pp. 29-42, 2003.

[7] P. B. Woelke, M. D. Shields, N. N. Abboud, and J. W. Hutchinson, "Simulations of ductile fracture in an idealized ship grounding scenario using phenomenological damage and cohesive zone models," Computational Materials Science, vol. 80, pp. 79-95, 2013.

[8] A. S. Wifi, A. Abdel-Hamid, H. El-Monayri, and N. El-Abbasi, "Finite element determination of workability limits for disks and rings under different upsetting conditions," Journal of Materials Processing Technology, vol. 56, no. 1-4, pp. 918-932, 1996. 
[9] S. Kobayashi, S. Oh, and T. Altan, Metal Forming and the FiniteElement Method, Oxford University Press, New York, NY, USA, 1989.

[10] R. H. Wagoner and J.-L. Chenot, Fundamentals of Metal Forming, John Wiley \& Sons, New York, NY, USA, 1997.

[11] R. Kiran and K. Khandelwal, "A micromechanical model for ductile fracture prediction in ASTM A992 steels," Engineering Fracture Mechanics, vol. 102, pp. 101-117, 2013.

[12] J.-K. Huang and X.-H. Dong, "A new ductile fracture criterion for various deformation conditions based on microvoid model," Journal of Iron and Steel Research International, vol. 16, no. 5, pp. 92-97, 2009.

[13] M. O. Ouali, M. Almansba, and N. Hannachi, "Ductile fracture prediction in bulk metal forming using multiscale and continuum damage mechanics models," in Proceedings of the International Conference on Computer Methods in Mechanics (CMM '11), Warsaw, Poland, May 2011.

[14] S. I. Oh, "Finite element analysis of metal forming processes with arbitrarily shaped dies," International Journal of Mechanical Sciences, vol. 24, no. 8, pp. 479-493, 1982.

[15] G. W. Rowe, C. E. N. Strugess, P. Hartley, and I. Pillinger, Finite-Element Plasticity and Metalforming Analysis, Cambridge University Press, Cambridge, UK, 1991.

[16] H. S. Valberg, Applied Metal Forming Including FEM Analysis, Cambridge University Press, Cambridge, UK, 2010.

[17] R. H. Wagoner and J.-L. Chenot, Metal Forming Analysis, Cambridge University Press, Cambridge, UK, 2001.

[18] LS-DYNA Aerospace Working Group, Modeling Guidelines Document Version 13-1, 2013.

[19] LS-DYNA, “Theory Manual” 2006.

[20] Y. Guo, "Meshless methods in LS-DYNA: an overview of EFG and SPH," in Proceedings of the LS-DYNA Seminar, 2010.

[21] P. J. G. Schreurs, F. E. Veldpaus, and W. A. M. Brekelmans, "Simulation of forming processes, using the arbitrary Eulerian-Lagrangian formulation," Computer Methods in Applied Mechanics and Engineering, vol. 58, no. 1, pp. 19-36, 1986.

[22] J.-P. Ponthot and M. Hogge, "The use of the EulerianLagrangian FEM in metal forming applications including contact and aadaptive mesh," in Proceedings of the ASME Symposium on Advances in Finite Deformation Problems in Material Processing and Structures, vol. 125, pp. 49-63, 1991.

[23] S. Ghosh and N. Kikuchi, "An arbitrary Lagrangian-Eulerian finite element method for large deformation analysis of elasticviscoplastic solids," Computer Methods in Applied Mechanics and Engineering, vol. 86, no. 2, pp. 127-188, 1991.

[24] W. K. Liu, T. Belytschko, and H. Chang, "An arbitrary lagrangian-eulerian finite element method for path-dependent materials," Computer Methods in Applied Mechanics and Engineering, vol. 58, no. 2, pp. 227-245, 1986.

[25] C. W. Hirt, A. A. Amsden, and J. L. Cook, "An arbitrary Lagrangian-Eulerian computing method for all flow speeds," Journal of Computational Physics, vol. 14, no. 3, pp. 227-253, 1974.

[26] J. Donea, P. Fasoli-Stella, and S. Giuliani, "Lagrangian and Eulerian finite element techniques for transient fluid-structure interaction problems," in Transactions of the 4th International Conference on Structural Mechanics in Reactor Technology, pp. $1-12,1977$.

[27] J. M. Kennedy and T. B. Belytschko, "Theory and application of a finite element method for arbitrary Lagrangian-Eulerian fluids and structures," Nuclear Engineering and Design, vol. 68, no. 2, pp. 129-146, 1982.

[28] J. Argyris, J. S. Doltsinis, H. Fischer, and H. Wüstenberg, "Ta panta rhei," Computer Methods in Applied Mechanics and Engineering, vol. 51, no. 1-3, pp. 289-362, 1985.

[29] D. J. Benson, "An efficient, accurate, simple ale method for nonlinear finite element programs," Computer Methods in Applied Mechanics and Engineering, vol. 72, no. 3, pp. 305-350, 1989.

[30] Y. Huang and Z. Dai, "Large deformation and failure simulations for geo-disasters using smoothed particle hydrodynamics method," Engineering Geology, vol. 168, pp. 86-97, 2014.

[31] M. F. Villumsen and T. G. Fauerholdt, Simulation of Metal Cutting using Smooth Particle Hydrodynamics, LS-DYNA Anwenderforum, Metallumformung III, Bamberg, Germany, 2008.

[32] M. Prakash, P. Cleary, and J. Grandfield, "Modelling of metal flow and oxidation during furnace emptying using smoothed particle hydrodynamics," Journal of Materials Processing Technology, vol. 209, no. 7, pp. 3396-3407, 2009.

[33] P. W. Cleary, M. Prakash, and J. Ha, "Novel applications of smoothed particle hydrodynamics (SPH) in metal forming," Journal of Materials Processing Technology, vol. 177, no. 1-3, pp. 41-48, 2006.

[34] J. Kordilla, A. M. Tartakovsky, and T. Geyer, "A smoothed particle hydrodynamics model for droplet and film flow on smooth and rough fracture surfaces," Advances in Water Resources, vol. 59, pp. 1-14, 2013.

[35] C. S. Li, X. H. Liu, and G. D. Wang, "Ring upsetting simulation by the meshless method of corrected smooth particle hydrodynamics," Journal of Materials Processing Technology, vol. 183, no. 2-3, pp. 425-431, 2007.

[36] H. Gedikli, "Crashworthiness optimization of foam-filled tailorwelded tube using coupled finite element and smooth particle hydrodynamics method," Thin-Walled Structures, vol. 67, pp. 34-48, 2013.

[37] Y. Michel, J.-M. Chevalier, C. Durin, C. Espinosa, F. Malaise, and J.-J. Barrau, "Hypervelocity impacts on thin brittle targets: experimental data and SPH simulations," International Journal of Impact Engineering, vol. 33, no. 1-12, pp. 441-451, 2006.

[38] Y. Wang, Y. Zhou, and Y. Xia, "A constitutive description of tensile behavior for brass over a wide range of strain rates," Materials Science and Engineering A, vol. 372, no. 1-2, pp. 186190, 2004.

[39] Y.-H. Xiao, C. Guo, and X.-Y. Guo, "Constitutive modeling of hot deformation behavior of H62 brass," Materials Science and Engineering A, vol. 528, no. 21, pp. 6510-6518, 2011.

[40] Livermore Software Technology Corporation (LSTC), LSDYNA Keyword User's Manual, Version 971, vol. 1, Livermore Software Technology Corporation (LSTC), 2007.

[41] S. Bala, "Viscosity for Shell and Solids in LS-DYNA," 2007, http://blog2.d3view.com/bulk-viscosity-for-shells-and-solidsin-ls-dyna/.

[42] C. Espinosa, J. L. Lacome, J. Limido, M. Salaun, C. Mabru, and R. Chieragatti, "Proceedings of the 10th International LSDYNA Users Conference, Metal Forming," in Proceedings of the 10th International LS-DYNA Users Conference, vol. 12 of Metal Forming (3), pp. 9-20, 2008.

[43] S. Bala and J. Day, General Guidelines for Crash Analysis in LSDYNA, Livermore Software Technology Corporation, 2012.

[44] S. Bala, SPH Contact Definitions, 2008, http://blog2.d3view .com/sph-contact-definitions/. 
[45] L. Olovsson, M. Souli, and I. Do, LS-DYNA-ALE Capabilities, (Arbitrary-Lagrangian-Eulerian), Fluid-Structure Interaction Modeling, 2003.

[46] D. Varas, R. Zaera, and J. López-Puente, "Numerical modelling of partially filled aircraft fuel tanks submitted to Hydrodynamic Ram," Aerospace Science and Technology, vol. 16, no. 1, pp. 19-28, 2012.

[47] J. Wang, Simulation of Landmine Explosion Using LS-DYNA3D Software, Aeronautical and Maritime Research Laboratory, 2001.

[48] M. A. Barsotti, "Modelling mind blast with SPH," in Proceedings of the 12th International LS-DYNA Users Conference, Blast/Impact (1), pp. 1-12, 2012.

[49] J. Day, Guidelines for ALE Modeling in LS-DYNA, 2009.

[50] B. Massey, Mechanics of Fluids, Taylor \& Francis, Abingdon, UK, 2006.

[51] H. Aretz, S. Keller, R. Vogt, and O. Engler, "Modelling of ductile failure in aluminium sheet forming simulation," International Journal of Material Forming, vol. 4, no. 2, pp. 163-182, 2011. 

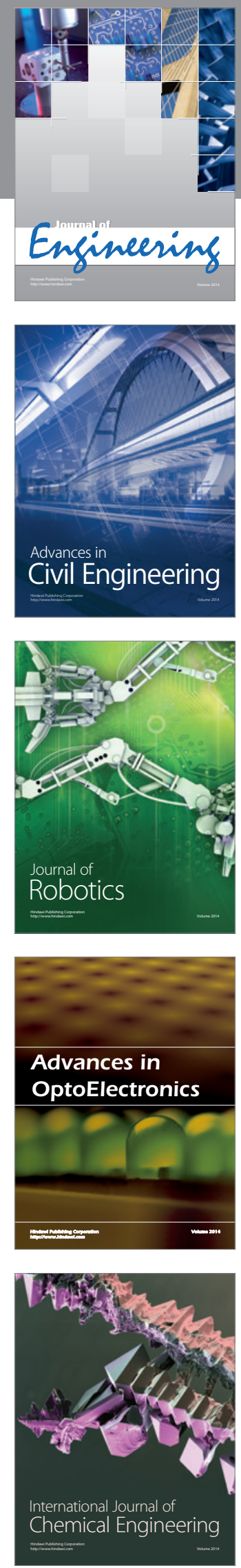

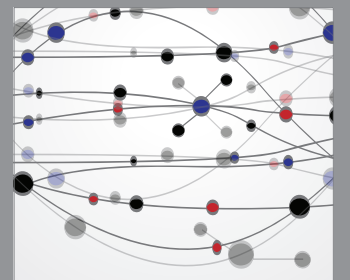

The Scientific World Journal
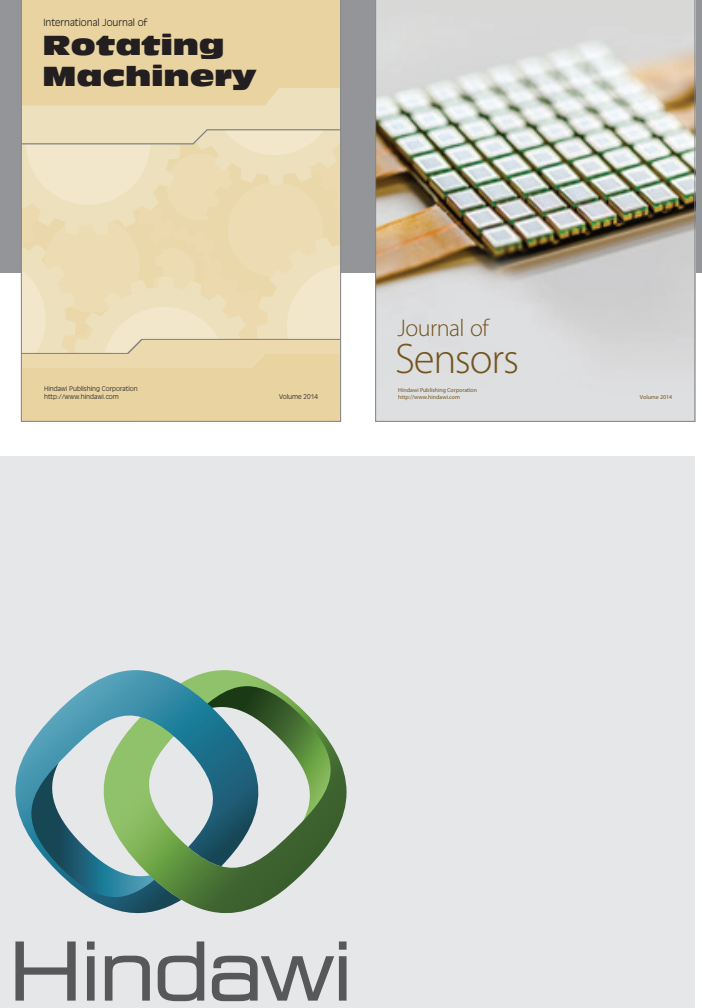

Submit your manuscripts at http://www.hindawi.com
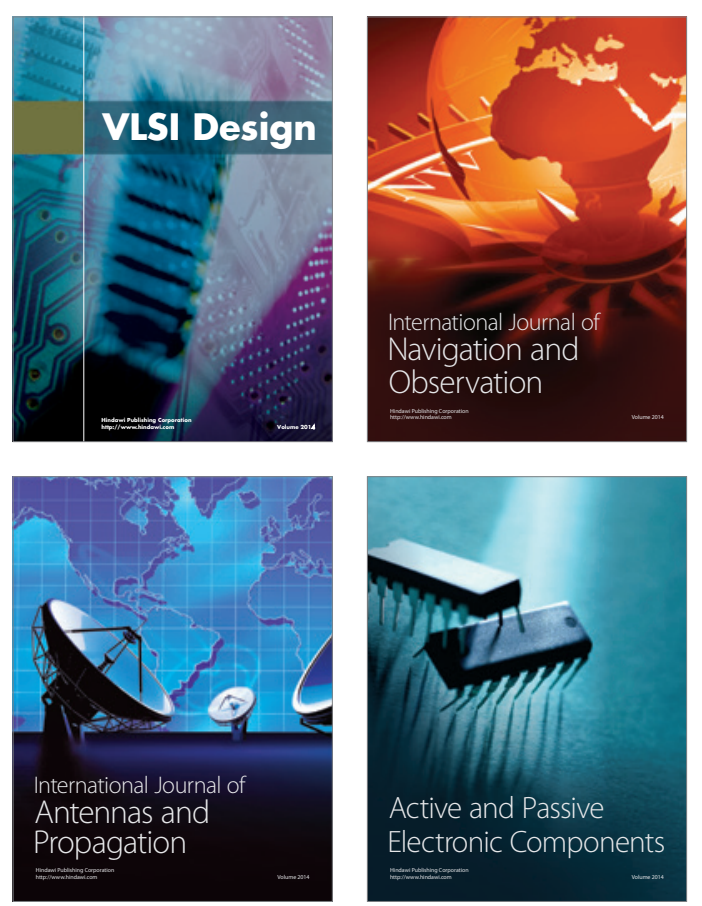
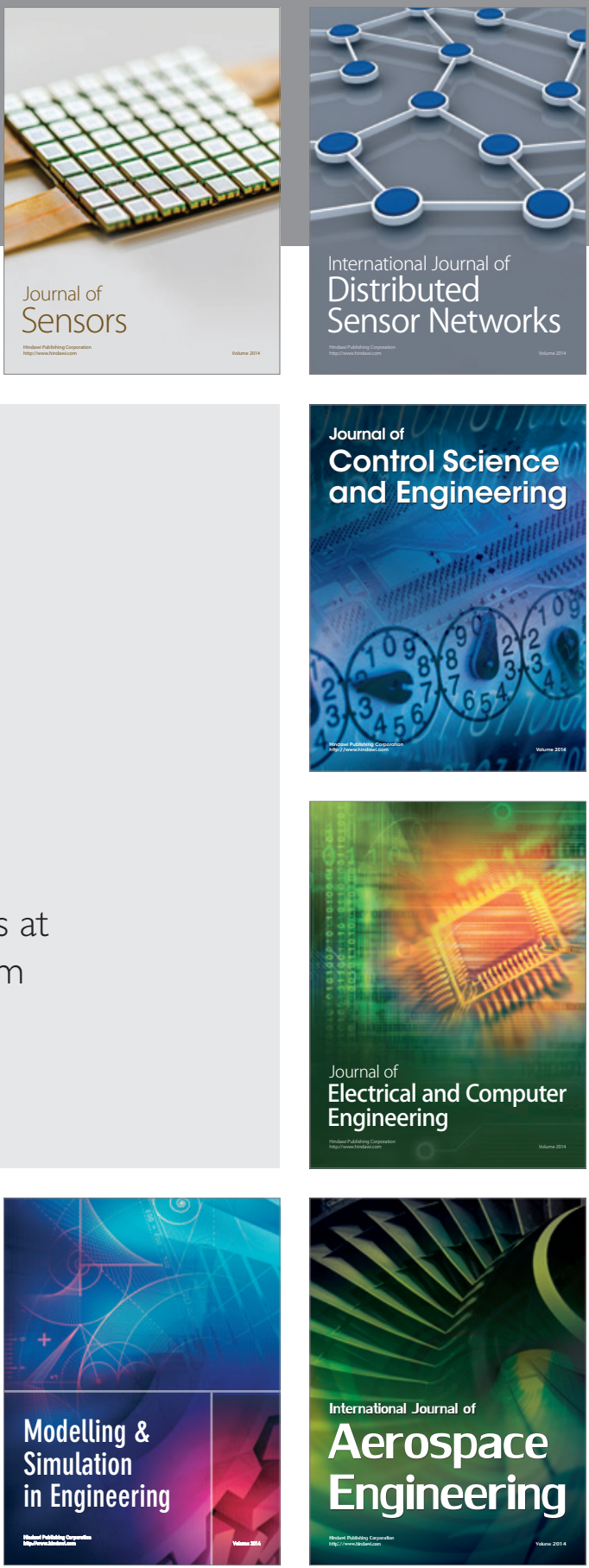

Journal of

Control Science

and Engineering
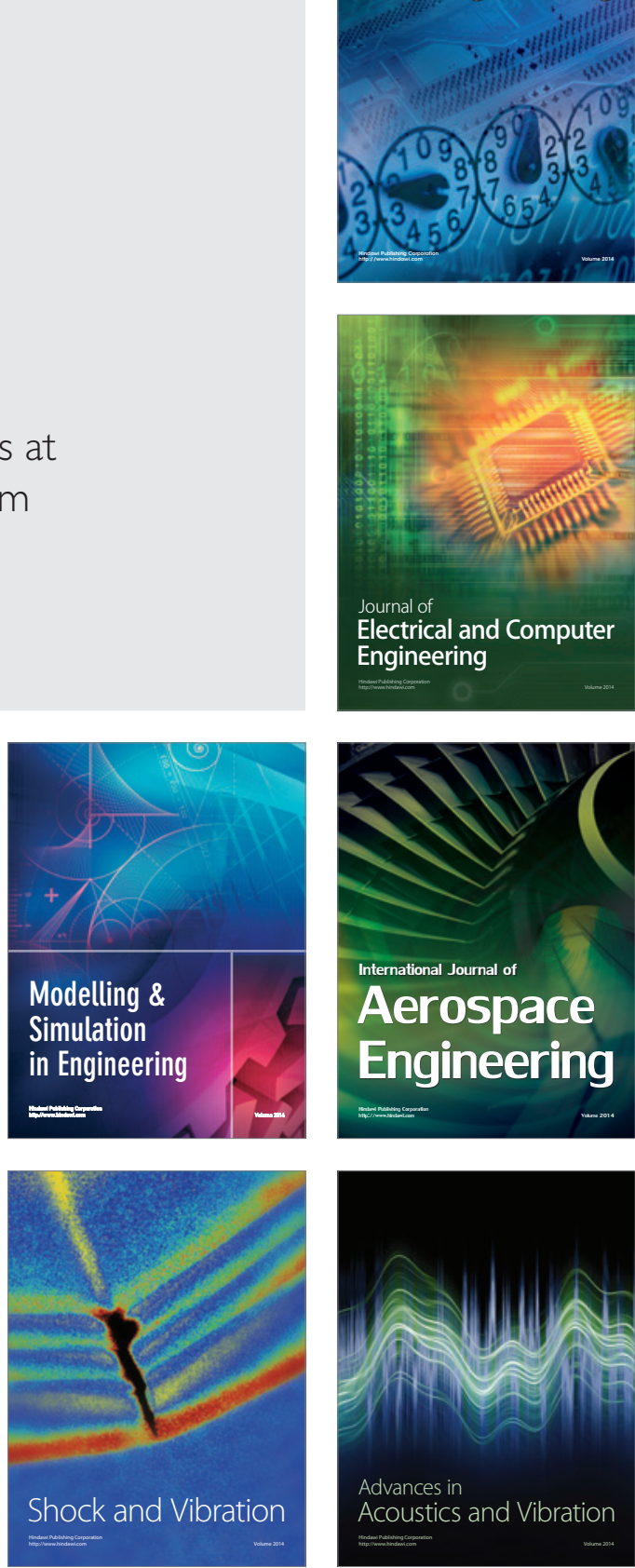